[Supporting Information]

\title{
Rapid microwave-assisted solid-phase glycopeptide synthesis
}

Takahiko Matsushita, ${ }^{\dagger}$ Hiroshi Hinou, ${ }^{\ddagger}$ Masaki Kurogochi, ${ }^{\dagger}$ Hiroki Shimizu, ${ }^{\ddagger}$ and Shin-Ichiro Nishimura ${ }^{*}, *$

${ }^{\dagger}$ Division of Biological Sciences, Graduate School of Science, Frontier Research Center for the Post-Genomic Science and Technology, Hokkaido University, N21, W11, Sapporo 001-0021, (Japan)

${ }^{\ddagger}$ Glycochemosynthesis Team, Research Center for Glycoscience, National Institute of Advanced Industrial Science and Technology (AIST), Sapporo 062-8517 (Japan)

\section{Experimental section}

\section{Materials and methods}

All commercially available solvents and reagents were used without further purification.

Fmoc-TentaGel resin functionalized with Rinkamide linker was purchased from Hipep Laboratories. All Fmoc-amino acids were purchased from Novabiochem. The Fmoc amino acids of $\operatorname{Arg}, A s p$, and His were employed as $\operatorname{Arg}(\mathrm{Pbf}), \operatorname{Asp}\left(\mathrm{O}^{\mathrm{t}} \mathrm{Bu}\right)$, and $\operatorname{His}(\operatorname{Trt})$. All solid-phase reactions for glycopeptide synthesis were performed manually in a 
polypropylene tube equipped with a filter. A general synthetic protocol using above protective groups and reagents was designed according to the conditions reported in the following papers: a) Carpino, L. A.; Shroff, H.; Triolo, S. A.; Mansour, E. -S. M. E.; Wenshuh, H.; Albericio, F. Tetrahedron Lett, 1993, 34, 7829-7832; b) Carpino, L. A.; Imazumi, H.; El-Faham, A.; Ferrer, F. J.; Zhang, C.; Lee, Y.; Foxman, B. M.; Henklein, P.; Hanay, C.; Mügge, C.; Wenschuh, H.; Klose, J.; Beyermann, M.; Bienert, M. Angew. Chem. Int. Ed. 2002, 41, 441-445. Swelling, washing, acetyl capping, and final cleavage procedures in the solid-phase syntheses were carried out at room temperature.

Glycopeptide synthesis with microwave irradiation was performed in a Green Motif I microwave synthesis reactor (IDX Corp.). The reaction vessel (polypropylene tube) was placed inside of the cavity of this instrument and was stirred with a vortex mixer. Single mode microwave was irradiated at $2450 \mathrm{MHz}$ using temperature control at $50{ }^{\circ} \mathrm{C}$.

Glycopeptide synthesis without microwave irradiation at $50{ }^{\circ} \mathrm{C}$ was performed in a VOS-601SD dry oven (TOKYO RIKAKIKAI Co. Ltd.). The reaction vessel was placed in a dry oven and was stirred with vortex mixer. The absorbance at $290 \mathrm{~nm}$ was monitored by using HITACHI U-2800 spectrophotometer in Fmoc photometric tests. ${ }^{1} \mathrm{H}-\mathrm{NMR}$ spectra of compound 1a and $\mathbf{1 b}$ were recorded with Bruker AVANCE 400 spectrometer at $400 \mathrm{MHz}$. FAB mass spectra were obtained with a JEOL JMS-HX110 
mass spectrometer, using $m$-nitrobenzylalcohol (NBA) as matrix.

Preparation of matrix-sample crystals for MALDI. Sinapinic acid (CHCA) or 2,5-dihyroxybenzoic acid (DHB) were used as matrix. The matrix solutions were prepared as described follows: DHB (10 mg) was dissolved in water (1 ml), and CHCA was prepared as saturated solution in 3:1 (v/v) of acetonitrile/water. Stock solutions of oligosaccharides and glycopeptides were prepared by dissolving them in pure water. A $0.5 \mu \mathrm{l}$ of matrix solution was applied on the target spot of Anchorchip plate ${ }^{\mathrm{TM}}$ (Bruker Daltonics) which was equipped with 384 hydrophilic anchors on an otherwise hydrophobic surface and allowed to add $1 \mu$ of the sample solution, and then dried at room temperature. We employed these samples (about 1-10 pmol) with TOF/TOF mode using the above preparation procedure.

MALDI-TOF mass spectrometry. All measurements were performed using an Ultraflex TOF/TOF mass spectrometer equipped with a reflector, and controlled by the Flexcontrol 1.2 software package (Bruker Daltonics GmbsH, Bremen, Germany) according to the general protocols reported in the previous papers (ref. 10). In MALDI TOF-MS reflector mode, ions generated by a pulsed UV laser beam (nitrogen laser, $\lambda$ 
$=337 \mathrm{~nm}, 5 \mathrm{~Hz}$ ) were accelerated to a kinetic energy of $23.5 \mathrm{kV}$. Metastable ions

generated by laser-induced decomposition of the selected precursor ions were analyzed

without any additional collision gas.

In MALDI-TOF/TOF mode, precursor ions were accelerated to $8 \mathrm{kV}$ and selected in a timed ion gate. The fragments were further accelerated by $19 \mathrm{kV}$ in the LIFT cell (LIFT means "lifting" the potential energy for the second acceleration of ion source), and their masses were analyzed after the ion reflector passage. Masses were automatically annotated by using FlexAnalysis 2.0 software package. External calibration of MALDI mass spectra was carried out using singly charged monoisotopic peaks of a mixture of human angiotensin II (m/z 1046.542), bombesin (m/z 1619.823), ACTH (18-39) (m/z 2465.199), and somatostatin $28(\mathrm{~m} / \mathrm{z}$ 3147.472). The mixture of these peptides was measured on the central spot of a 3 x 3 square by using external calibration. To achieve mass accuracy better than $60 \mathrm{ppm}$, internal calibration was carried out by doping the matrix solution with a mixture of the calibration peptides. Calibration of these mass spectra was performed automatically by utilizing a customized macro command of the FlexControl 2.1 software package. The macro command was used for the calibration of the monoisotopic singly charged peaks of the above mentioned peptides. TOF/TOF spectra were annotated with the BioTools 2.1 software package. 


\section{Synthesis of sugar amino acids.}

$O$ - $\{2$-Acetamido- $O$-[2-acetamido-3,4,6-tri- $O$-acetyl-2-deoxy- $\beta$-D-glucopyranosyl-( $1 \rightarrow$ 6)]-2-deoxy-O-[2,3,4,6-tetra- $O$-acetyl- $\beta$-D-galactopyranosyl-( $1 \rightarrow 3)]$ - $\alpha$-D-galactopyran osyl $\}-N^{\alpha}$-(fluoren-9-ylmethoxycarbonyl)-L-threonine tert-butyl ester was synthesized according to the procedure reported previously (ref. 7).

Selected spectral data (Fig. S-1): ${ }^{1} \mathrm{H}-\mathrm{NMR}\left(400 \mathrm{MHz}, \mathrm{CDCl}_{3} ; \mathrm{Me}_{4} \mathrm{Si}\right) \delta$ 7.80-7.32 (8 H,

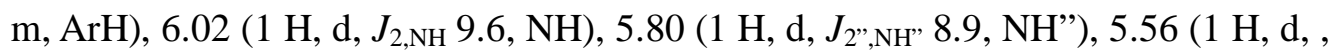
$J_{\mathrm{CH}}^{\alpha}{ }_{, N H} 8.9, \mathrm{NH}$ Thr), 5.37 (1 H, , $\left.J_{3}, 4^{\prime}, 2.9,4^{\prime}-\mathrm{H}\right)$, 5.19-5.13 (2 H, m, 2'-H and 3'- $\left.-\mathrm{H}\right)$, 5.09-5.05 (1 H, dd, 4’'-H), 4.98-4.96 (1 H, dd, 3'-H), 4.79 (1 H, d, J1,2 3.4, 1-H), 4.59 (2 H, $2 \mathrm{~d}, J_{1,2}, 8.0,1$ '-H and $J_{1 ", 2}, 8.0,1$ '”-H), 4.55-4.45 (3 H, m, Fmoc $\mathrm{CH}_{2}$ and 2-H), 4.28-4.23

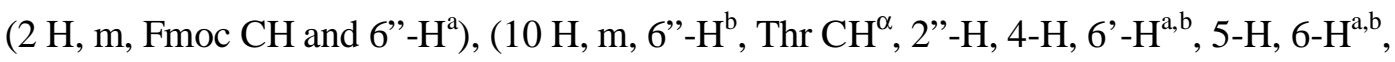
and Thr $\left.\mathrm{CH}^{\beta}\right), 3.77$ (1 H, dd, 5-H), 3.69-3.66 (2 H, m, 3-H and 5"-H), 2.80 (1 H, br s, 4-OH), 2.16, 2.08, 2.07, 2.02, 1.99, 1.98, 1.90 and $1.78\left(27 \mathrm{H}, 8 \mathrm{~s}, 9 \times \mathrm{COCH}_{3}\right), 1.46(9 \mathrm{H}$, $\left.\mathrm{s}, \mathrm{Bu}^{\mathrm{t}}\right)$ and $1.27\left(3 \mathrm{H}, \mathrm{d}\right.$, Thr $\left.\mathrm{CH}^{\gamma}\right)$. HRMS-FAB (m/z), calcd. for $\mathrm{C}_{59} \mathrm{H}_{78} \mathrm{~N}_{3} \mathrm{O}_{27}(\mathrm{M}+\mathrm{H})$ : 1260.4823; found: 1260.4850

$O$-\{2-Acetamido- $O$-[2-acetamido-3,4,6-tri- $O$-acetyl-2-deoxy- $\beta$-D-glucopyranosyl-(1 
$\rightarrow 6)]$-2-deoxy-O-[2,3,4,6-tetra- $O$-acetyl- $\beta$-D-galactopyranosyl-(1 $\rightarrow 3)]$ - $\alpha$-D-galacto pyranosyl\}- $N^{\alpha}$-(fluoren-9-ylmethoxycarbonyl)-L-threonine (1a).

tert-Butyl group of the above precursor was cleaved by treating with a solution of $50 \%$ TFA in DCM at room temperature for $30 \mathrm{~min}$. The mixture was co-evaporated with toluene. The residue was dissolved in $30 \%$ aq. $\mathrm{CH}_{3} \mathrm{CN}$ and lyophilized to give 1a. An analytical RP-HPLC profile of 1a was shown in Fig. S-3 (a). HRMS-FAB (m/z), calcd. for $\mathrm{C}_{55} \mathrm{H}_{70} \mathrm{~N}_{3} \mathrm{O}_{27}(\mathrm{M}+\mathrm{H}):$ 1204.4197; found: 1204.4194

$O$ - $\{2$-Acetamido- $O$-[2-acetamido-3,4,6-tri- $O$-acetyl-2-deoxy- $\beta$-D-glucopyranosyl-( $1 \rightarrow$ 6)]-2-deoxy-O-[2,3,4,6-tetra- $O$-acetyl- $\beta$-D-galactopyranosyl-( $1 \rightarrow 3)]-\alpha$-D-galactopyran osyl $\}-N^{\alpha}$-(fluoren-9-ylmethoxycarbonyl)-L-serine tert-butyl ester was also synthesized according to the previous report (ref. 7).

Selected spectral data (Fig. S-2): ${ }^{1} \mathrm{H}-\mathrm{NMR}\left(400 \mathrm{MHz}, \mathrm{CDCl}_{3} ; \mathrm{Me}_{4} \mathrm{Si}\right) \delta$ 7.80-7.31 (8 H,

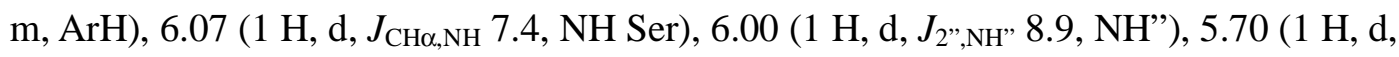
$J_{2, \mathrm{NH}}$ 8.8, NH), 5.37-5.32 (2 H, m, 4'-H and 3'-H), 5.22-5.15 (1 H, m, 2'-H), 5.05-4.95 (2 H, m, 3'-H and 4"'-H), 4.77 (1 H, d, $\left.J_{1,2} 3.4,1-\mathrm{H}\right), 4.69$ (1 H, d, $J_{1 ", 2}$, 7.6, 1"'-H), 4.56-4.40 (5 H, m, 1'-H, 2-H, Fmoc $\mathrm{CH}_{2}$, Ser $\mathrm{CH}^{\alpha}$ ), 4.27-4.21 (2 H, m, 6"-H', Fmoc CH), 4.20-3.59

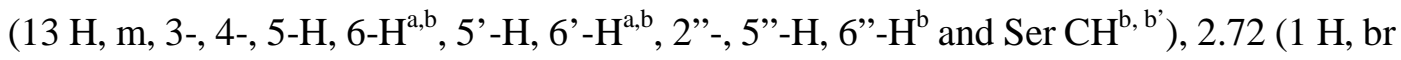


$\mathrm{s}, 4-\mathrm{OH}), 2.16,2.06,2.05,2.02,1.98,1.95,1.89$ and $1.81\left(27 \mathrm{H}, 8 \mathrm{~s}, 9 \times \mathrm{COCH}_{3}\right)$ and $1.50\left(9 \mathrm{H}, \mathrm{s}, \mathrm{Bu}^{\mathrm{t}}\right)$. HRMS-FAB (m/z), calcd. for $\mathrm{C}_{58} \mathrm{H}_{76} \mathrm{~N}_{3} \mathrm{O}_{27}(\mathrm{M}+\mathrm{H}):$ 1246.4666; found: 1246.4642 .

$O$-\{2-Acetamido- $O$-[2-acetamido-3,4,6-tri- $O$-acetyl-2-deoxy- $\beta$-D-glucopyranosyl-(1 $\rightarrow 6)]$-2-deoxy-O-[2,3,4,6-tetra- $O$-acetyl- $\beta$-D-galactopyranosyl-(1 $\rightarrow 3)]$ - $\alpha$-D-galacto pyranosyl\}- $N^{\alpha}$-(fluoren-9-ylmethoxycarbonyl)-L-serine (1b)

Compound $\mathbf{1 b}$ was prepared by a similar procedure described in the preparation of $1 \mathbf{a}$. An analytical RP-HPLC profile of 1b was shown in Fig. S-3 (b). HRMS-FAB (m/z), calcd. for $\mathrm{C}_{54} \mathrm{H}_{68} \mathrm{~N}_{3} \mathrm{O}_{27}(\mathrm{M}+\mathrm{H}): 1190.4040$; found: 1190.4048

\section{Preparation of preloaded Ala-resin}

To Fmoc-TentaGel resin functionalized with Rinkamide linker (548 mg, $0.14 \mathrm{mmol}$ ) swollen in DMF (10 ml) for 30 min was added 20\% piperidine/DMF $(10 \mathrm{ml})$ and the mixture was stirred for 20 min. The resin was filtered and washed with DMF $(5 \times 10 \mathrm{ml})$. Fmoc-Ala-OH (3.0 equiv.) was assembled onto the resin by treating with HBTU (3.0 equiv.), HOBt (3.0 equiv.) and DIEA (6.0 equiv.) in DMF (1.03 ml) and the resin was stirred for $2 \mathrm{~h}$ at room temperature. Quantification of Fmoc-Ala-residue attached onto 
the resin was confirmed by measuring UV absorption at $290 \mathrm{~nm}$ correspond to the

dibenzofulvene-piperidine adduct. Deprotection of Fmoc group was achieved with $20 \%$ piperidine/DMF (10 ml) for $20 \mathrm{~min}$. Finally the Ala-resin was filtered and washed with DMF $(5 \times 10 \mathrm{ml})$ and DCM $(5 \times 10 \mathrm{ml})$, then dried over in vacuo for 24 hours.

\section{Coupling reaction of compound (1a) with the Ala-resin.}

Coupling of $1 \mathbf{a}(1.5$ equiv. $)$ with Ala-resin $(0.26 \mathrm{mmol} / \mathrm{g})(15 \mathrm{mg}, 3.90 \mu \mathrm{mol})$ was performed in the presence of HBTU (1.5 equiv.), HOBt (1.5 equiv.), and DIEA (3.0 equiv.) in DMF $(100 \mu \mathrm{l})$. The mixture was stirred by using vortex mixer under suitable conditions (microwave at $50^{\circ} \mathrm{C}$, non-microwave at $50^{\circ} \mathrm{C}$, and non-microwave at room temperature) for appropriate time. Coupling reaction was stopped by filtration and the resin was washed with DMF $(5 \times 1 \mathrm{ml})$ and DCM $(5 \times 1 \mathrm{ml})$. The resulting resin was dried over in vacuo.

\section{Determination of coupling yields by photometric test.}

The amount of Fmoc groups on the resin was determined as substitution level of $\mathbf{1 a}$ on the Ala-resin. To the resin $(1.0 \mathrm{mg})$ weighed out was added $20 \%$ piperidine/DMF $(1 \mathrm{ml})$ and was stirred at room temperature for $20 \mathrm{~min}$. The absorbance of the sample solution 
was read at $290 \mathrm{~nm}\left(\varepsilon=5800 \mathrm{M}^{-1} \mathrm{~cm}^{-1}\right)$ in a quartz cell. Duplicate measurements were carried out and the average was substituted in the following equation 1 to obtain experimental Fmoc loading.

experimental Fmoc loading $(\mathrm{mmol} / \mathrm{g})=\frac{\mathrm{OD}_{290} \times 1000}{5800 \times(\mathrm{mg} \text { of resin })}$

Coupling yields were calculated by comparison of experimental Fmoc loading with the theoretical loading. The theoretical loading corresponding to $100 \%$ of reaction proceeding was calculated by the following equation 2 .

theoretical loading $(\mathrm{mmol} / \mathrm{g})=\frac{A \times 1000}{1000+A \times(B-239)}$

$A$ : loading of starting resin $(\mathrm{mmol} / \mathrm{g})$

$B$ : molecular weight of the target glycopeptide involved all protecting groups

\section{Solid-phase synthesis of glycopeptide 2 under microwave irradiation (entry 1 in}

Table 1). Coupling reactions and removal of Fmoc protection were conducted under microwave irradiation at $50^{\circ} \mathrm{C}$. To Fmoc-TentaGel Rinkamide resin $(50 \mathrm{mg}, 12.5 \mu \mathrm{mol})$ swollen in DMF (1 ml) for 30 min was added and stirred with 20\% piperidine/DMF (1 $\mathrm{ml})$ for $3 \mathrm{~min}$, then the resin was filtered and washed with $\mathrm{DMF}(5 \times 1 \mathrm{ml})$. The appropriate Fmoc-amino acids (3.0 equiv.) were incorporated to the resin with HBTU 
(3.0 equiv.), HOBt (3.0 equiv.), and DIEA (6.0 equiv.) in DMF (660 $\mu \mathrm{l})$ for $10 \mathrm{~min}$.

Coupling reactions of $\mathbf{1 a}$ and $\mathbf{1 b}$ (1.5 equiv.) were carried out with HBTU (1.5 equiv.), HOBt (1.5 equiv.), and DIEA (3.0 equiv.) in DMF (330 $\mu \mathrm{l})$ for 20min. After coupling reaction, the resin was washed with $\operatorname{DMF}(5 \times 1 \mathrm{ml})$. The un-reacted amino groups were capped by acetylation with $13 \mathrm{mM} \mathrm{HOBt}$ in $\mathrm{Ac}_{2} \mathrm{O} / \mathrm{DIEA} / \mathrm{DMF}$ solution (4.75:2.25:93.0, $\mathrm{v} / \mathrm{v} / \mathrm{v}, 1 \mathrm{ml}$ ) for $5 \mathrm{~min}$ and the resin was washed with DMF. Fmoc deprotection was conducted by treatment with $20 \%$ piperidine/DMF (1 ml) for $3 \mathrm{~min}$ and washed with $\operatorname{DMF}(5 \times 1 \mathrm{ml}) . \quad$ After completion of the glycopeptide elongation on the solid-phase, the glycopeptidyl-resin was washed with DMF $(5 \times 1 \mathrm{ml})$ and DCM $(5 \times 1 \mathrm{ml})$ and dried over in vacuo for $24 \mathrm{~h}$.

\section{Solid-phase synthesis of glycopeptide 2 under non-microwave condition at $50^{\circ} \mathrm{C}$}

\section{(entry 2 in Table 1).}

All coupling reactions and removal of Fmoc groups were conducted under heating at 50 ${ }^{\circ} \mathrm{C}$ in a dry oven. To Fmoc-Rinkamide resin $(50 \mathrm{mg}, 12.5 \mu \mathrm{mol})$ swollen in DMF $(1 \mathrm{ml})$ for $30 \mathrm{~min}$ was added and stirred with $20 \%$ piperidine/DMF (1 ml) for $3 \mathrm{~min}$, then the mixture was filtered and washed with $\mathrm{DMF}(5 \times 1 \mathrm{ml})$. The appropriate Fmoc-amino acids (3.0 equiv.) were incorporated to the resin with HBTU (3.0 equiv.), HOBt (3.0 
equiv.), and DIEA (6.0 equiv.) in DMF (660 $\mu \mathrm{l})$ for 10 min. Coupling reactions of $1 \mathbf{a}$

and $\mathbf{1 b}$ (1.5 equiv.) were carried out with HBTU (1.5 equiv.), HOBt (1.5 equiv.), and DIEA (3.0 equiv.) in DMF (330 $\mu \mathrm{l})$ for 20 min. The resin was washed with DMF $(5 \times 1$ $\mathrm{ml}$ ) and the un-reacted amino groups were capped by acetylation with $13 \mathrm{mM} \mathrm{HOBt}$ in $\mathrm{Ac}_{2} \mathrm{O} / \mathrm{DIEA} / \mathrm{DMF}$ solution $(4.75: 2.25: 93.0, \mathrm{v} / \mathrm{v} / \mathrm{v}, 1 \mathrm{ml})$ for $5 \mathrm{~min}$ and the resin was washed with DMF. Deprotection of Fmoc groups was conducted by treatment with $20 \%$ piperidine/DMF $(1 \mathrm{ml})$ for $3 \mathrm{~min}$ and the resin was washed with DMF $(5 \times 1 \mathrm{ml})$. After completion of the glycopeptide elongation on the solid-phase, the glycopeptidyl-resin was washed with DMF $(5 \times 1 \mathrm{ml})$ and DCM $(5 \times 1 \mathrm{ml})$, and dried over in vacuo for $24 \mathrm{~h}$.

\section{Solid-phase synthesis of glycopeptide 2 using a standard protocol at room} temperature (entry 3 in Table 1).

All coupling reactions and deprotection of Fmoc groups were conducted at room temperature. To Fmoc-Rinkamide resin $(50 \mathrm{mg}, 12.5 \mu \mathrm{mol})$ swollen in DMF $(1 \mathrm{ml})$ for 30 min was added and stirred with $20 \%$ piperidine/DMF $(1 \mathrm{ml})$ at room temperature for $20 \mathrm{~min}$, then filtered and washed with DMF $(5 \times 1 \mathrm{ml})$. The appropriate Fmoc-amino acids (3.0 equiv.) were incorporated to the resin with HBTU (3.0 equiv.), HOBt (3.0 equiv.), and DIEA (6.0 equiv.) in DMF (660 $\mu \mathrm{l})$ at room temperature for $2 \mathrm{~h}$. Coupling 
reactions of $1 \mathbf{a}$ and $\mathbf{1 b}$ (1.5 equiv.) were carried out with HBTU (1.5 equiv.), HOBt (1.5 equiv.), and DIEA (3.0 equiv.) in DMF (330 $\mu \mathrm{l})$ at the same condition for $12 \mathrm{~h}$. After coupling reaction, the resin was washed with $\mathrm{DMF}(5 \times 1 \mathrm{ml})$. The un-reacted amino groups were capped by acetylation with $13 \mathrm{mM} \mathrm{HOBt}$ in $\mathrm{Ac}_{2} \mathrm{O} / \mathrm{DIEA} / \mathrm{DMF}$ solution $(4.75: 2.25: 93.0, \mathrm{v} / \mathrm{v} / \mathrm{v}, 1 \mathrm{ml})$ for $5 \mathrm{~min}$ at room temperature and the resin was washed with DMF. Deprotection of Fmoc groups was conducted by treatment with $20 \%$ piperidine/DMF $(1 \mathrm{ml})$ at room temperature for $20 \mathrm{~min}$ and the resin was washed with $\operatorname{DMF}(5 \times 1 \mathrm{ml})$. After completion of the synthesis on the solid-phase, the glycopeptidyl-resin was washed with DMF $(5 \times 1 \mathrm{ml})$ and DCM $(5 \times 1 \mathrm{ml})$, and dried over in vacuo for $24 \mathrm{~h}$.

\section{Determination of overall reaction yields of glycopeptide 2 by photometric test.}

The amount of existing Fmoc groups on the resulting resin synthesized in the conditions tested (microwave at $50{ }^{\circ} \mathrm{C}$, non-microwave at $50{ }^{\circ} \mathrm{C}$, and a standard protocol at room temperature) was determined as achievement level of glycopeptide elongation. All procedures and calculations of reaction yields were carried out in the same manner as described above. 


\section{Reversed-phase HPLC analysis of a crude glycopeptide 2 released from resin}

Dried glycopeptidyl-resins prepared for entries 1, 2, and 3 in Table 1 (each $3.0 \mathrm{mg}$ ) were treated with TFA/triisopropylsilane (TIS)/DCM (400 $\mu$ l, 95/2.5/2.5, v/v/v) under

vigorous stirring for 2 hours at room temperature. The mixture was concentrated by

streaming of nitrogen gas. Then, $50 \%$ aq. $\mathrm{CH}_{3} \mathrm{CN}(1 \mathrm{ml})$ was added to the residue and

the solution was lyophilized to give $0.97 \mathrm{mg}, 0.92 \mathrm{mg}$, and $0.93 \mathrm{mg}$ of crude

glycopeptides in entry 1, 2, and 3, respectively. Each crude glycopeptide was dissolved in $30 \%$ aq. $\mathrm{CH}_{3} \mathrm{CN}$ containing $0.1 \%$ TFA $(75 \mu \mathrm{l})$. These solutions $(20 \mu \mathrm{l})$ were directly loaded onto HPLC column. HPLC analysis was performed with GL sciences C18 reversed-phase column (Inertsil ODS-3, $\phi 4.6 \times 250 \mathrm{~mm}$ ). Flow rate was $1.0 \mathrm{ml} / \mathrm{min}$ and elution conditions were described as follows: elution buffer (A) $0.1 \%$ aq. TFA, elution buffer (B) $\mathrm{CH}_{3} \mathrm{CN}$ containing 0.1\% TFA, 0-5min: constant flow $(\mathrm{A} / \mathrm{B})=(70 / 30)$, 5-45min: linear gradient flow $(\mathrm{A} / \mathrm{B})=(10 / 90)$, and 45-50min: constant flow $(\mathrm{A} / \mathrm{B})=$ (10/90). UV absorbance was measured at 220nm.

Structural characterization of compound $\mathbf{2}$ and other by-products isolated by HPLC was carried out by means of MALDI-TOF/TOFMS and the results were represented in Figure S-5. 


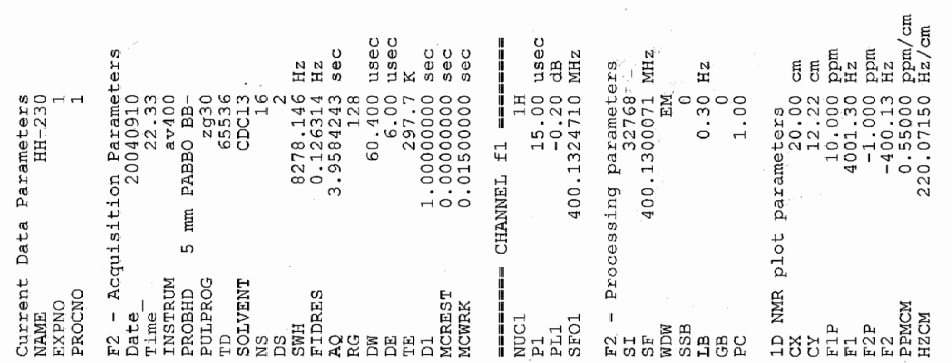

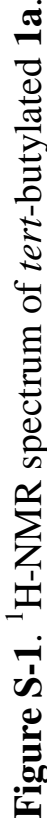

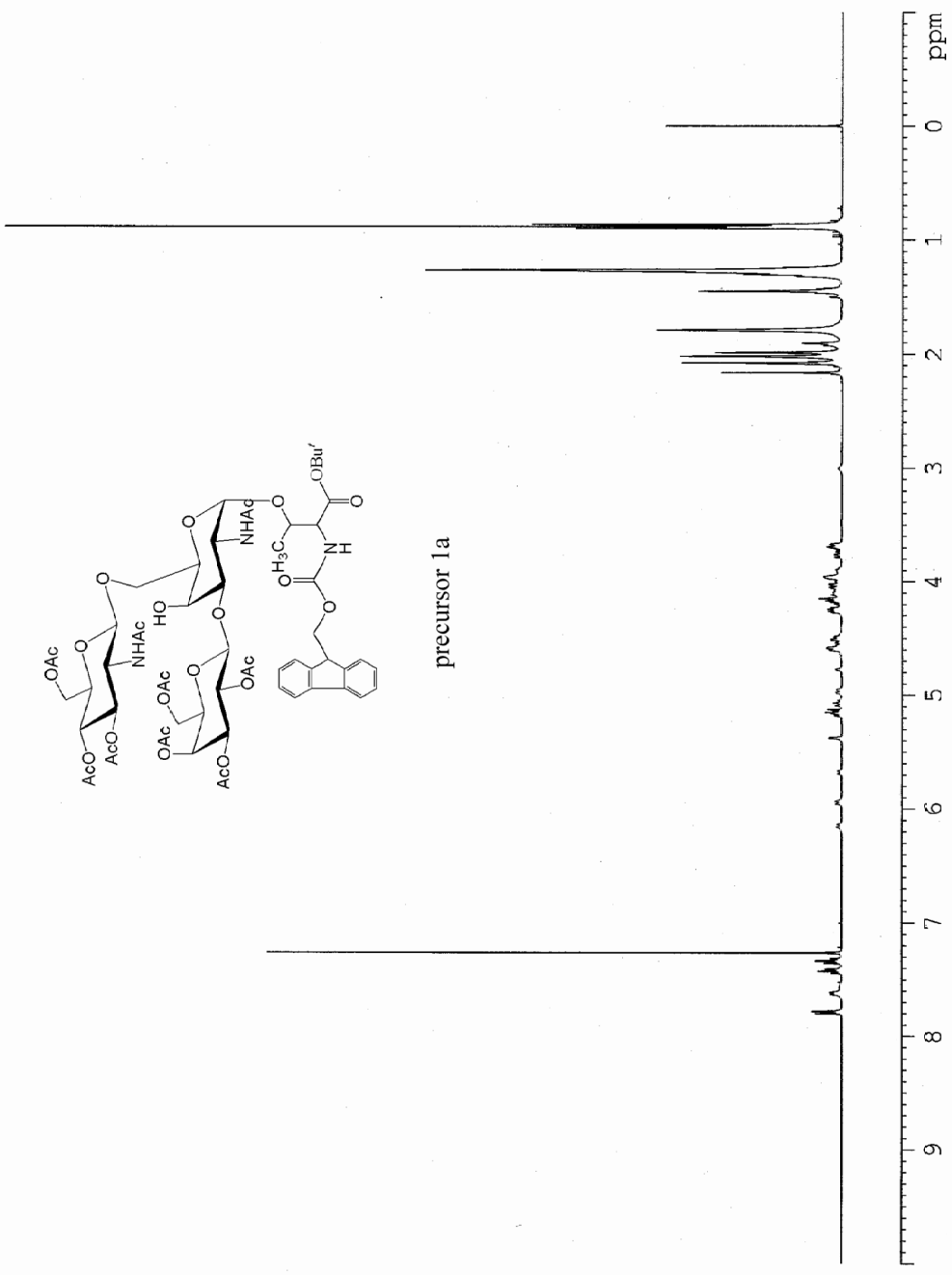




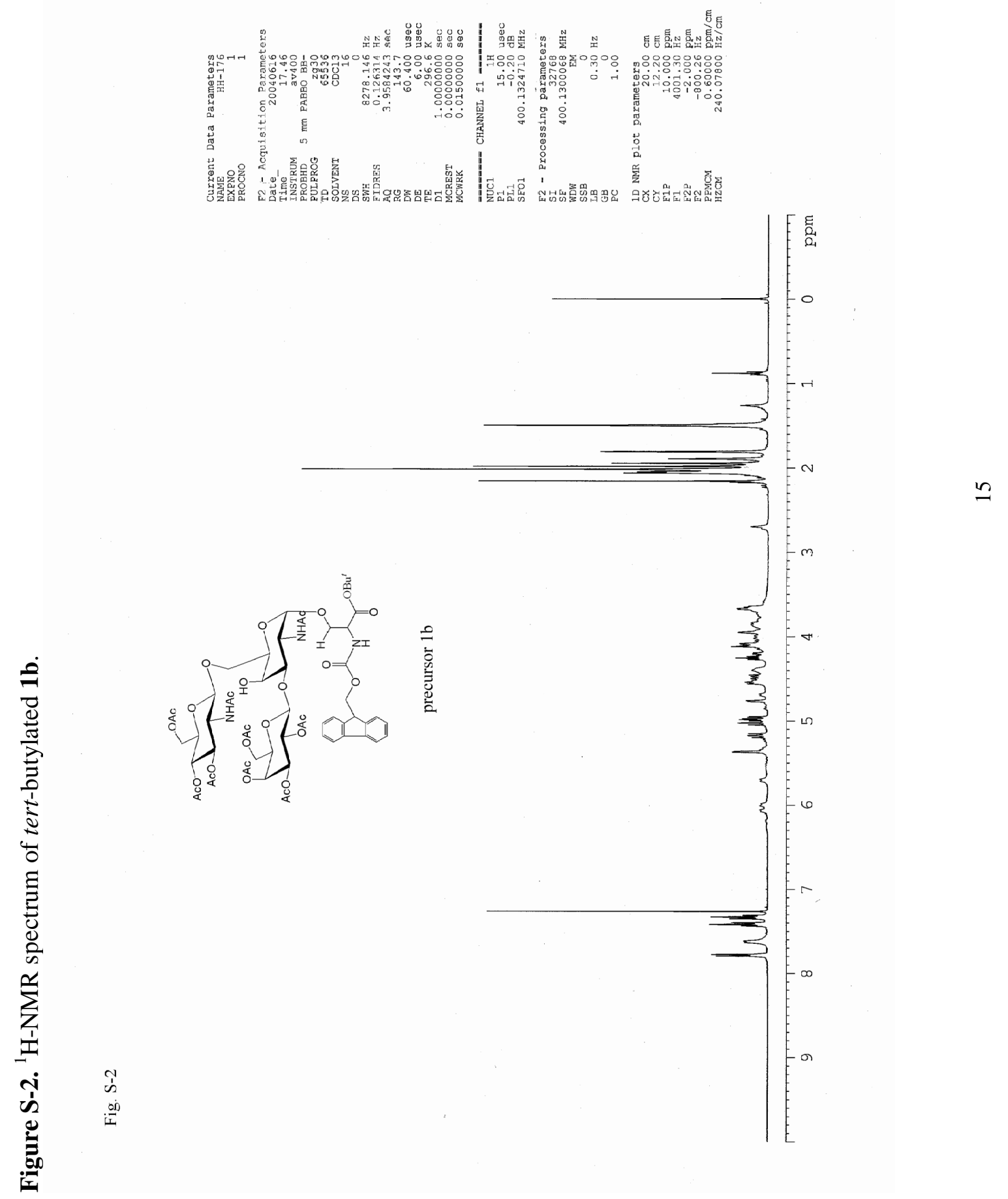


Figure S-3. Analytical HPLC profiles of glycosylated amino acid building blocks 1a (a) and 1b (b). Column: Inertsil ODS-3, C-18 $(4.6 \times 250 \mathrm{~mm})$, Flow Rate: $1 \mathrm{ml} / \mathrm{min}$, elution buffer: (A) $0.1 \%$ aq. TFA, elution buffer (B) $\mathrm{CH}_{3} \mathrm{CN}$ containing $0.1 \%$ TFA, $0-5$ min: constant flow $(\mathrm{A} / \mathrm{B})=(90 / 10), 5-45$ min: linear gradient flow $(\mathrm{A} / \mathrm{B})=(10 / 90)$. UV absorbance was measured at $220 \mathrm{~nm}$.

(a)

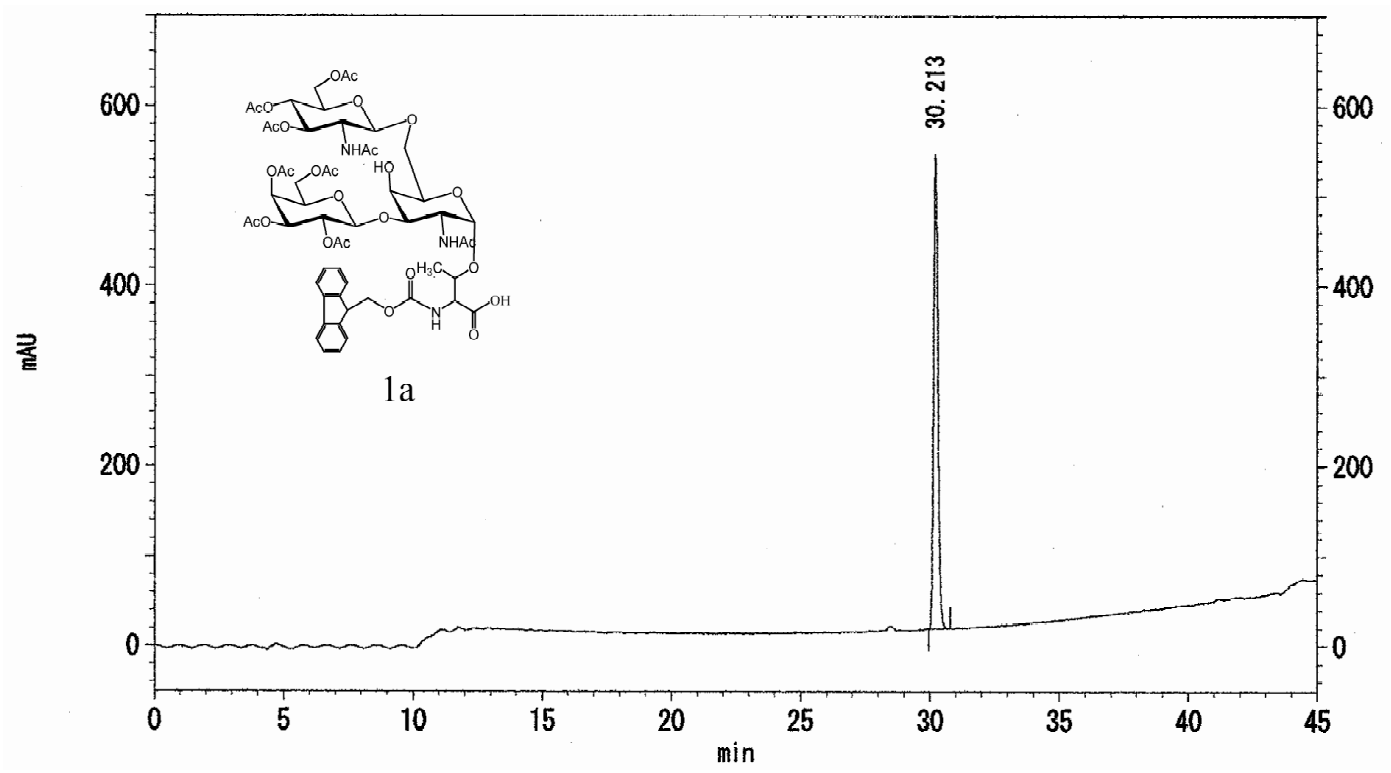

(b)

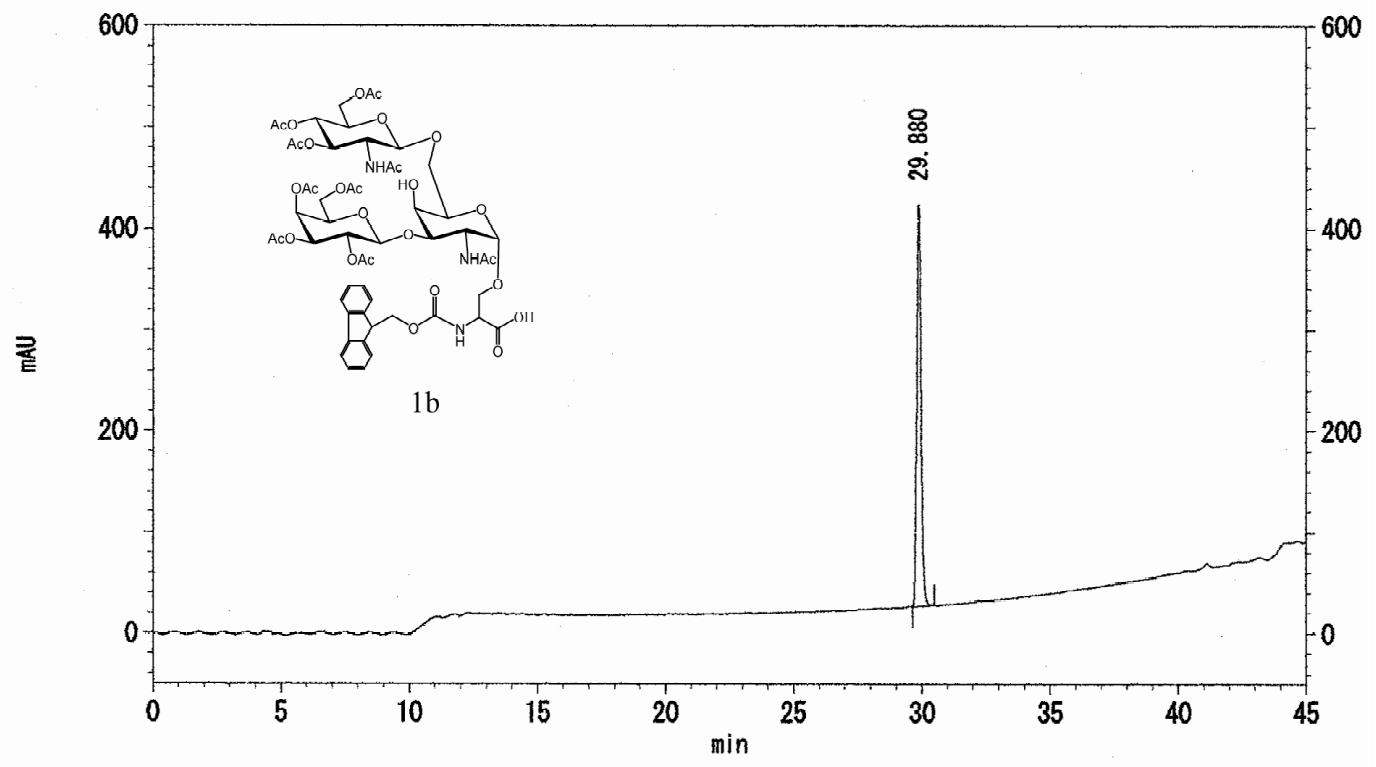


Figure S-4. MALDI-TOFMS of the crude glycopeptide 2 synthesized under microwave irradiation at $50{ }^{\circ} \mathrm{C}(\mathrm{a})$, without microwave irradiation at $50{ }^{\circ} \mathrm{C}(\mathrm{b})$, and a standard protocol at room temperature (c).

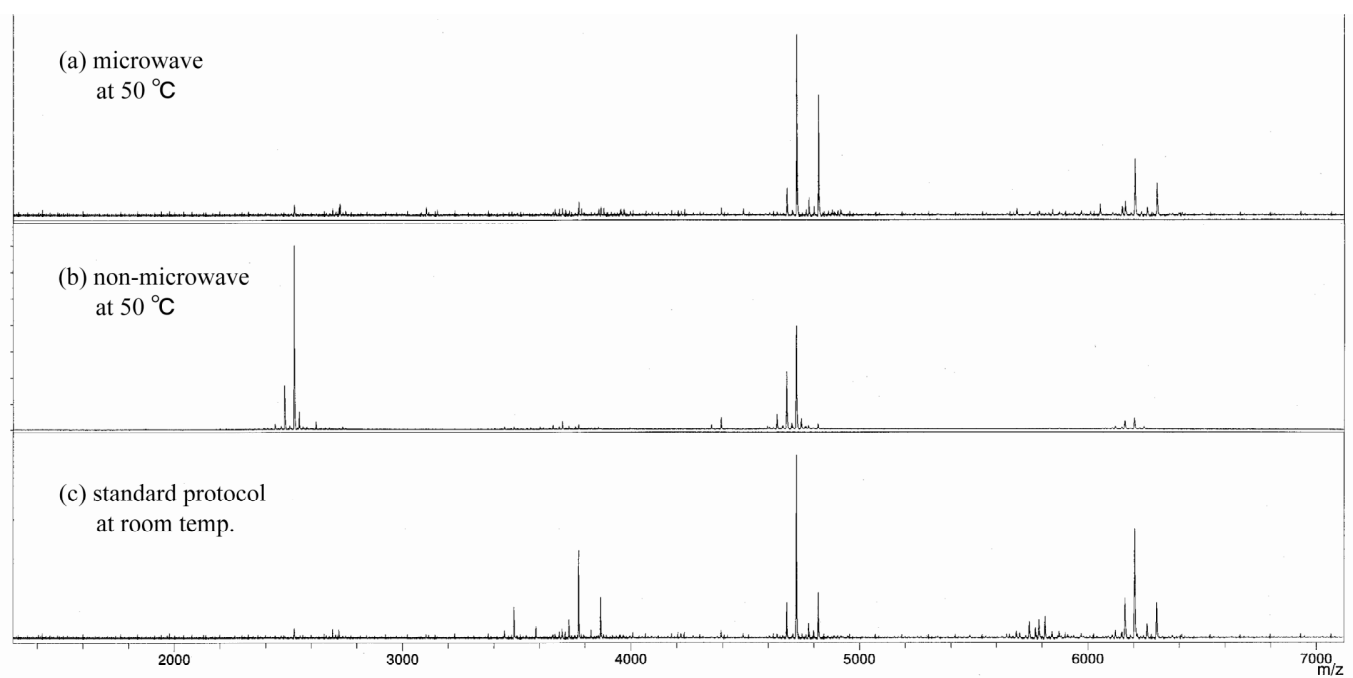


Figure S-5. Structural characterization of the compound $\mathbf{2}$ and other by-products by means of MALDI-TOF/TOFMS

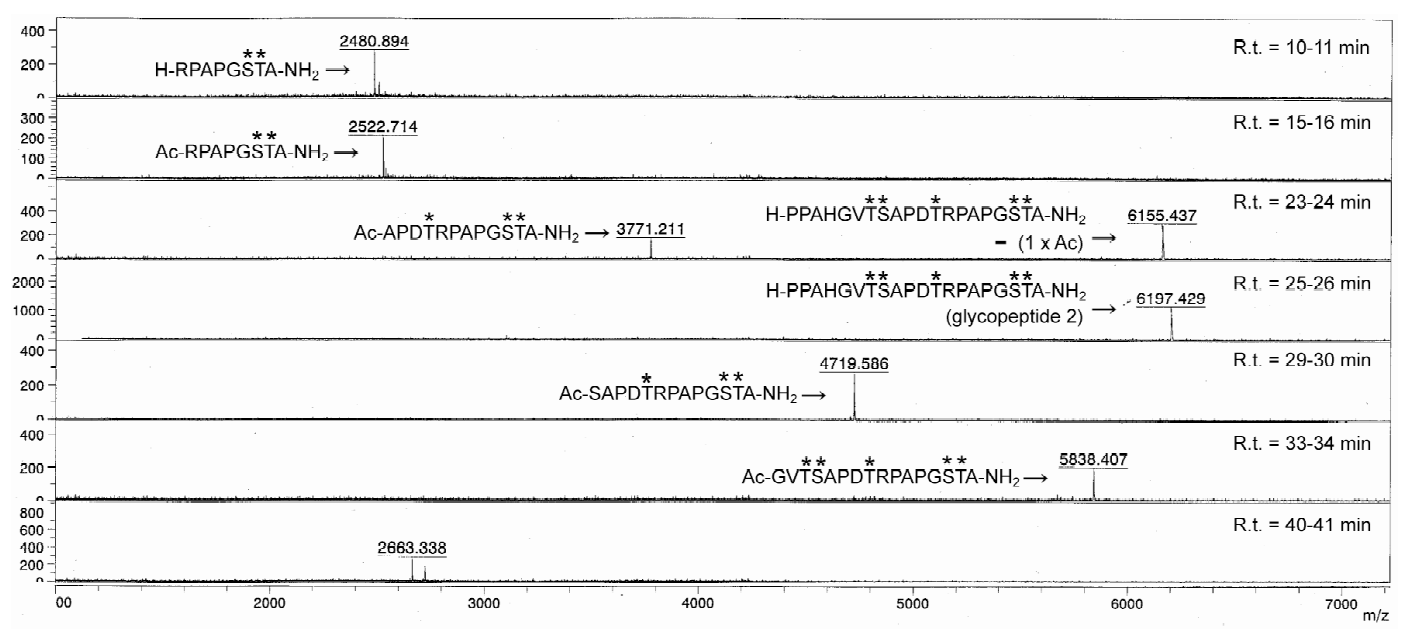

Fractions at 40-41 min were the mixture of some minor by-products with small molecular weights and their precise structural characterization could not be carried out. 